\title{
Pre and Post Column Derivatization of Amino Acid - A Systematic Review of HPLC
}

\section{CH Prudhviraju ${ }^{1 *}$, J Swaminathan ${ }^{2}$, K Sri Nataraj ${ }^{3}$ and B Rajasekhar ${ }^{1}$}

${ }^{1}$ Department of Pharmaceutical Analysis, Shri Vishnu College of Pharmacy

(Autonomous), Affiliated to Andhra University, Bhimavaram, India

${ }^{2}$ Assistant Professor, Delhi Pharmaceutical Sciences and Research University, Govt

of NCT of Delhi, India

${ }^{3}$ Professor, Department of Pharmaceutical Analysis, Shri Vishnu College of

Pharmacy (Autonomous), Affiliated to Andhra University, Bhimavaram, India

*Corresponding Author: CH Prudhviraju, Department of Pharmaceutical Analysis,

Shri Vishnu College of Pharmacy (Autonomous), Affiliated to Andhra University,

Bhimavaram, India.
Received: July 14, 2021

Published: July 29, 2021

(C) All rights are reserved by $\mathbf{C H}$ Prudhviraju., et al.

\begin{abstract}
Derivatization is a technique that converts a compound into products of similar chemical structure, a derivative. Sensitivity enhancement and selectivity can be achieved by deviantization. Derivatization is required to alter retention characteristics, increase response to various detection techniques and provide selective response for analytes in complex matrices. Sensitivity enhancement became very important for the analysis and determination of peptide hormones, their metabolites and fragments, trace constituents and amino acids existing in very little quantity in biological and clinical samples. Amino acids in various foods may occur as free amino acids, or in the form of peptides, proteins or bonded in non-peptide polymers. The nutrition value or enhancement of flavour, aroma, taste or appearance in wine and fruits juices is mainly due to presence of free amino acids. The main contribution of this work lies in descriptive study of amino acid analysis by pre-column and post-column derivatization. Derivatization enables the analyst to analyse a wide variety of compounds by HPLC, GC, LC-MS and GC-MS that were less volatile and unstable for these techniques. This study shall help analyst to gain knowledge on pre-and post-column derivatization. Both the methods have their own advantages and disadvantages. Amino acid analysis plays a crucial role in fields like food science, clinical diagnostics and pharmaceutical product research. In general analytical derivatization is for two main reasons first is for permit analysis of compounds with inadequate volatility (or) stability. Second one is for improve chromatographic behaviour or detectability.
\end{abstract}

Keywords: HPLC; GC; LC-MS; GC-MS; Derivatization and PCD

List of Symbols

$>, \mu, \%, \leq$.

\section{Abbreviations}

HPLC: High Performance Liquid Chartography; GC: Gas Chromatography; LC-MS: Liquid Chromatography Mass Spectroscopy; GC-
MS: Gas Chromatography Mass Spectroscopy; PCD: Post-column Derivatization; PITC: Phenyl Isothiocyanate; GSH: Glutathione; NAC: N-acetylcysteine; CL: Chemiluminescence; DMF: Dimethylformamide; $\mathrm{N}_{2} \mathrm{CH}_{2}$ : Diazomethane; PFBBr: Penta Fluorobenzyl Bromide; PFBHA: Penta Fluorobenzyl Hydroxylamine Hydrochloride; 
TBH: Tetra Butyl Ammonium Hydroxide; BSA: Bis (trimethylsilyl)acetamide; BSTFA: Bis (trimethylsilyl) tri-fluoroacetamide; MSTFA: N-methyl-trimethylsilyl Trifluoroacetamide; HMDS: Hexamethyldisilzane; TMCS: Trimethyl Chlorosilane; TMSI: Trimethylsilyl Imidazole; TMS-DEA: Trimethyl Diethylamine; MTBSTFA: N-methyl-N-t-butyl Dimethyl Silyl Trifluoroacetamide; tBDMS: Tert-butyl Dimethyl Silyl; TFAA: Trifluoroacetic Anhydride; PFPA: Pentafluoro Propionic Anhydride; HFBA: Heptafluorobutyric Anhydride; TFAI: Trifluoroacetylimidazole; ECD: Electron Capture Detectors; MBTFA: N-Methyl-bis(trifluoroacetamide); PFBCI: Pentafluorobenzyl Chloride; PFPOH: 4-Pentafluoro Propanol; 4-CB: 4-Carbethoxyhexafluorobutyl Chloride; TPC: N-trifluoro acetyl-L-prolyl Chloride; 1-TPC: (S)- (-)-N- (Trifluoro acetyl)-prolyl Chloride; MTPA: (-)- $\alpha$-Methoxy - $\alpha$-trifluoromethylphenyl Acetic Acid; OPA: o-phthalaldehyde; RP-HPLC: Reverse Phase-High Pressure Liquid Chromatography; AFT: Active Flow Technology; FLD: Fluorescence Detection; RF: Reaction Flow; FMOC: 9-Fluorenylmethyl-chloroformate; RP-UPLC: Ultra-High Performance Liquid Chromatography; AQC: Amino Quinolyl-N-hydroxysuccinimidyl Carbamate; CE: Capillary Electrophoresis.

\section{Introduction}

High-performance liquid chromatography (HPLC) is the analytical technique used for the separation of analytical compounds. The HPLC is combined with post-column derivatization (PCD) technique, it is a powerful tool used for solving various problems in the analytical laboratory [1]. It is useful to detect compounds with suitable detectors available, increases the signals of analyte. This technique is used to enhance the lower limits of detection and quantification of target analyte and then it is derivatized in order to avoid matrix effect. The post-column derivatization (PCD) reactions are usually amines such as amino acids react with o-phthalaldehyde, ninhydrin or fluoresceine.

Pre and post-column derivatizations are the column techniques fused in HPLC for increasing the selectivity and sensitivity [2]. The post column derivatization technique is a criteria designed to increase or optimize the analyte reactivity. The post-column derivatization (PCD) techniques also effect on enhancement of signal strength without altering the chromatographic efficiency or reproductivity. Derivatization methods are used in HPLC for the detection of compounds that cannot be detected by using existing detectors. Generally, proteins are consisting of amino acids and play a wide role in the nutrition.
Amino acids are the biochemical compounds, they are formed by acid catalysed hydrolysis of polypeptide and protein, but only 20 amino acids are naturally occurring from polypeptides which are referred to as standard amino acids. The pre-column derivatization techniques are mostly used for the analysis of amino acids like $o$-phthalaldehyde, phenyl isothiocyanate (PITC), fluoresceine and dansyl chloride. Due to absence of chromophore and hydrophilicity of amino glycosides and lake of volatility, some derivatizing agents and techniques are applied to improve their chromatographic performance [3]. Generally, antioxidants involved in body protection mechanism and agents are reactive oxygen species. Amino acids such as glutathione (GSH) and $\mathrm{N}$-acetylcysteine (NAC) are involved in production of agent's oxidative lethality.

Aflatoxins $\mathrm{B}_{1}$ Aflatoxins $\mathrm{B}_{2}$, Aflatoxins $\mathrm{G}_{1}$ and Aflatoxins $\mathrm{G}_{2}\left(\mathrm{AFB}_{1}\right.$, $\mathrm{AFB}_{2}, \mathrm{AFG}_{1}, \mathrm{AFG}_{2}$ ) they are secondary metabolites are moulds aspergillus flavus and aspergillus parasitic. Novel pre-column derivatization have been developed by these samples based on magnetic solid-phase [4]. Amino acids are the basic constituents of proteins. Amino acid analysis used to establish the composition of amino acid or content of proteins and peptides. So, quantitative and qualitative analysis of amino acids composition of hydrolysed samples are used to identify and measure the concentration of a particular sample. Generally, amino acid analysis procedure includes hydrolysis, separation, detection, and quantification. A protein sample or peptide sample is hydrolysed before amino acid analysis and then free amino acids are separated by HPLC and detected by using an appropriate detector. Pre- and/or post-column derivatization methods have been used to improve sensitivity and selectivity of the analysis amino acids. The various amino acids are polarized by plausible poly probiotic conditions on mineral surfaces such as clays and soluble salts to form varying amounts of oligomers [5]. Peroxyborate chemiluminescence (CL) is a highly sensitive detection for HPLC and having detection limits in the low femtomole and even attomole range.

\section{Derivatization reagent}

They are chemically modify a compound to produce a new product or compound for easy analysis in LC, HPLC and GC.

Characteristics for choosing derivatization reagents in chromatograms:

- The reagent should produce the derivatives, those were not react with column. 
- The derivatizing reagents should produce the derivatives with in the short time.

- Derivatizing agent should not cause the loss of the sample during the reaction

- $\quad$ Reagent should not cause the structural alternatives during the process of derivatization

- The reagent should have the potency to produce $95 \%$ of derivatives [6].

\section{Objectives for derivatization:}

- Derivatization is mainly for reduce tailing factor and in the improvement of resolution for the compounds which contains $-\mathrm{OH},-\mathrm{COOH},=\mathrm{NH}$ and $-\mathrm{NH}_{2}$ functional groups.

- Derivatization process is for stabilization of compound and also for improvement of detectability.

- Derivatization is for analysis of relatively non-volatile compounds.

\section{Classifications of derivatizations}

The derivatization reactions are categorized based on selection of reagent and type of substitution reaction:

- Alkylation

- Silylation

- Acylation

Alkylation

The procedure involves protection of active hydrogens in a sample molecule by the replacement of active hydrogen with aliphatic or aliphatic- aromatic group by esterification process. Ex: - Benzyl group. Derivatization reagents in Alkylation:

\section{Dialkyl acetals}

Dimethylformamide (DMF) is an example of dialkyl acetals with a general formula $\mathrm{CH}_{3} \mathrm{CH}_{3} \mathrm{NCHOROR}$ are used to esterify acids to their methyl esters. Organic acids are converts into esters. Derivatives of methyl esters generating the better chromatograms than free acids.

\section{Diazoalkales}

Diazomethane $\left(\mathrm{N}_{2} \mathrm{CH}_{2}\right)$ is the main reagent in the diazoalakales group responsible for preparation of methyl esters. In this proce- dure methanol is used as catalyst in fatty acid reaction for forming methyl esters from diazomethane.

Penta fluorobenzyl bromide (PFBBr) and Penta fluorobenzyl hydroxylamine hydrochloride (PFBHA)

Penta fluorobenzyl bromide $\left(\mathrm{C}_{7} \mathrm{H}_{2} \mathrm{H}_{5} \mathrm{Br}\right)$ and pentafluorobenzylhydroxylamine hydrochloride are used to esterify the compounds like phenols, thiols and carboxylic acids.

\section{Benzyl bromide}

Benzyl bromide has the property to generate or increase the volatility of the analyte of interest. Esters are formed by the reaction of benzyl bromide with acid part of an alkyl acid.

\section{Tetrabutyl ammonium hydroxide (TBH)}

- $\quad$ TBH is mostly used for estimation of low molecular weight acids and low molecular weight amines.

- Ex- When carboxylic acid treated with TBH a derivatized product like butyl ester was formed, which is having longer retention time in GC column.

- $\quad$ TBH is most suitable derivatizing reagent for analysing biological fluid and thermally stable fatty acids by flash alkylation.

Boron trifluoride $\left(\mathrm{BF}_{3}\right)$ in methanol or butanol

The $\mathrm{BF}_{3}$ reagent reacts with acids to form the methyl (butyl) esters. $\mathrm{BF}_{3}$ reagent is convenient and inexpensive method for forming esters.

As per F3B: HO-CnH2n+1 if $n$ is 1 methanol as well as if $n$ is 4 $\mathrm{n}$-butanol is formed.

Alkylation derivatization technique and reagents selection based on sample types F. Orata., et al. in 2012.

\section{Silylation}

Silylation is the most commonly used method for the derivatization of non-volatile chemical compounds into volatizes samples. It was the best method suitable for the volatile sample's analysis in chromatography. This method is the introduction of a silyl group into a molecule.

\section{Silylation order for functional groups}

Alcohols $>$ Phenols $>$ Carboxyl $>$ Amine $>$ Amides/Hydroxyl. 


\begin{tabular}{|l|c|}
\hline Functional group & Derivatization reagent \\
\hline $\begin{array}{l}\text { Alcohols and } \\
\text { Phenols }\end{array}$ & $\begin{array}{c}\text { Dimethylformamide, Pentafluorobenzyl } \\
\text { bromide }\end{array}$ \\
\hline Carboxylic acids & $\begin{array}{c}\text { Dimethylformamide, Tetrabutylammo- } \\
\text { nium hydroxide Bis(trimethylsilyl)-acet- } \\
\text { amide }\end{array}$ \\
\hline Active hydrogens & $\begin{array}{c}\text { Dimethylformamide, Tetrabutylammo- } \\
\text { nium hydroxide }\end{array}$ \\
\hline Amides & Dimethylformamide \\
\hline Amines & Dimethylformamide (Diacetals) \\
\hline Amino acids & $\begin{array}{c}\text { Dimethylformamide, Tetrabutylammo- } \\
\text { nium hydroxide }\end{array}$ \\
\hline Nitrosamine & $\begin{array}{c}\text { Dimethylformamide, Pentafluorobenzyl } \\
\text { bromide }\end{array}$ \\
\hline
\end{tabular}

Table a

Silylation order for alcohols

primary $>$ secondary $>$ tertiary.

Bis (trimethylsilyl)-acetamide (BSA)

BSA is a strong silylating reagent because acetamide group in BSA acts as leaving group and produces a suitable by-product. In some cases, the by-product of trimethylsilyl-acetamide sometimes produce unknown peaks which may overlap with other volatile derivatives.

\section{Bis (trimethylsilyl) tri-fluoroacetamide (BSTFA)}

$\mathrm{N}, \mathrm{N}$-bis (trimethyl-silyl) trifluoro-acetamide (BSTFA) is the popular reagent for silylation. BSTFA reacts rapidly with organic acids to give high yields with low detector noise and fouling. High volatility of BSTFA results in early eluting of peaks.

N-methyl-trimethylsilyl trifluoroacetamide (MSTFA)

MSTFA is most useful method for analysis of volatile trace materials where the derivatives may be the by-product or reagent peak.

\section{Hexamethyldisilzane (HMDS)}

HMDA has symmetry. HMDS is used to attack only easily silylated hydroxyl groups.
Trimethyl chrorosilane (TMCS)

TMCS reacts with acids to produces the by-product as a hydrochloric acid. To the BSTFA the TMCS is added to catalyses reactions of hindered functional groups in secondary alcohols and amines. It is not commonly used.

Trimethylsilyl imidazole (TMSI)

TMSI selectively reacts with alcohols and phenols but not reacts with amines or amides (nitrogen groups). TMSI target the hydroxyls in wet sugars and also derivatize the acid site of amino acids and leaves the amino group free for fluorinated derivatization. TMSI is not a weak donor.

\section{Trimethyl diethylamine (TMS-DEA)}

Amino acids, antibiotics, urea-formaldehyde condensates, steroids and carboxylic acids are derivatized by TMS-DES. The byproduct has a high volatility, it is eluted with the solvent or reagent and usually does not interfere with the chromatogram.

N-methyl-N-t-butyl dimethyl silyl trifluoroacetamide (MTBSTFA)

MTBSTFA reagent replaces the active hydrogen with tert-butyl dimethyl silyl (t-BDMS) group. The t-BDMS derivatives are more resistant to hydrolysis and they are 1000 times more stable than TMS derivatives.

Silylation derivatization technique and reagents selection based on sample types F. Orata., et al. in 2012.

\section{Acylation}

Thioesters, amides and esters are generated by acylation of active hydrogens (e.g., -OH, -SH and -NH). It is also popular method for the production of volatile derivatives and also generating highly polar and in volatile organic materials. Stable derivatized samples are produced by acylation.

\section{Fluorinated anhydrides}

- $\quad$ Trifluoroacetic anhydride (TFAA)

- Pentafluoro propionic anhydride (PFPA)

- Heptafluorobutyric anhydride (HFBA)

The acidic by-products are formed by reaction between perfluoro acid anhydrides and acyl and halide reagents for the chro- 


\begin{tabular}{|c|c|}
\hline Functional group & Derivatization reagent \\
\hline $\begin{array}{l}\text { Alcohols and Phe- } \\
\text { nols }\end{array}$ & $\begin{array}{c}\text { Bis(trimethylsilyl)-acetamide, } \\
\text { Bistrimethylsilyltrifluoroacetamide, } \\
\text { N-methyl-N-tbutyldimethylsilyltrifluo- } \\
\text { roacetamide } \\
\text { Heptafluorobutyrylimidazole, } \\
\text { Pentafluoropropionic }\end{array}$ \\
\hline Carboxylic acids & $\begin{array}{l}\text { Bistrimethylsilyltrifluoroacetamide, } \\
\text { Trimethylsilyl imidazole, } \\
\text { N-methyl-N-t-butyldimethylsilyltrifluo- } \\
\text { roacetamide }\end{array}$ \\
\hline Active hydrogens & $\begin{array}{l}\text { Bistrimethylsilyltrifluoroacetamide/ } \\
\text { Trimethylchlorosilane, Hydroxy-Sil, N- } \\
\text { methyl-trimethylsilyl trifluoroacetamide }\end{array}$ \\
\hline $\begin{array}{l}\text { Carbohydrates and } \\
\text { Sugars }\end{array}$ & $\begin{array}{l}\text { Hexamethyldisilane, Trimethylsilyl } \\
\text { imidazole }\end{array}$ \\
\hline Amides & $\begin{array}{c}\text { Bis(trimethylsilyl)-acetamide, } \\
\text { N, O-bis-(trimethylsilyl)- trifluoroacet- } \\
\text { amide }\end{array}$ \\
\hline Amines & $\begin{array}{l}\text { Bistrimethylsilyltrifluoroacetamide, } \\
\text { N-methyl-N-tbutyldimethylsilyltrifluo- } \\
\text { roacetamide }\end{array}$ \\
\hline Amino acids & $\begin{array}{c}\text { Bistrimethylsilyltrifluoroacetamide, } \\
\text { Trimethylsilyl imidazole }\end{array}$ \\
\hline Catecholamines & $\begin{array}{c}\text { Trimethylsilyl imidazole } \\
\text { Pentafluoropropionic Anhydride, }\end{array}$ \\
\hline Inorganic anions & $\begin{array}{l}\text { Bistrimethylsilyltrifluoroacetamide, } \\
\text { N-methyl-N-tbutyldimethylsilyltrifluo- } \\
\text { roacetamide }\end{array}$ \\
\hline Nitrosamine & Bistrimethylsilyltrifluoroacetamide \\
\hline Sulphides & Trimethylsilyl imidazole \\
\hline
\end{tabular}

Table b

matographic analysis. Which will prevent the damage to chromatographic column. The stable and highly volatile derivatives are produced by the reagents reacts with alcohols, amines and phenols.

\section{Fluorocylimidazoles}

Fluorocylimidazoles, Trifluoroacetylimidazole (TFAI) reagents should be handle carefully because they react violently with water.
They produce the by-product (imidazole and/or N-methyl trifluoroacetamide) are not acidic and therefore do not harm the column.

Heptafluorobutyrylimidazole forms derivatives with phenols, amines and they are suitable for electron capture detectors (ECD).

\section{N-Methyl-bis(trifluoroacetamide)(MBTFA)}

The reagent produces inert and non-acidic by-products and they do not cause the damage to the column. The MBTFA is rapidly reacts with primary and secondary amines and also slowly with hydroxyl groups and thiols.

\section{Pentafluorobenzyl chloride (PFBCI)}

Phenol and amino derivatives are formed by the reaction of PFBCI with alcohols and secondary amines. PFBCI forms the rapid derivatives of amines and phenols.

\section{4-Pentafluoro propanol (PFPOH)}

The PFPOH reagents reacts with polyfunctional bio-organic compounds to form the derivatives suitable for electron capture detector (ECD).

\section{4-Carbethoxyhexafluorobutyl chloride (4-CB)}

The excess agents are removed by adding protic solvents. 4-CB reacts with secondary amines to forms the stable products.

\section{GC Chiral derivatization}

The pure chiral derivatizing agents to form two diastereomeric derivatives which can be separated by using GC. The samples solution which contains both enantiomers of a compounds are present in equal amounts is called a racemic mixture.

\section{Separation of enantiomers by chromatography}

- Separation on an optically active stationary phase.

- preparation of diastereomeric derivatives that can be separated on a non-chiral stationary phase.

\section{Reagents}

- $\quad$ N-trifluoro acetyl-L-prolyl chloride (TPC)

- (S)-(-)-N-(Trifluoro acetyl)-prolyl chloride (1-TPC)

- (-)- $\alpha$-Methoxy - $\alpha$-trifluoromethylphenyl acetic acid (MTPA)

Acylation derivatization technique and reagents selection based on sample types F. Orata., et al. in 2012. 


\begin{tabular}{|c|c|}
\hline $\begin{array}{l}\text { Functional } \\
\text { group }\end{array}$ & Derivatization reagent \\
\hline $\begin{array}{l}\text { Alcohols and } \\
\text { Phenols }\end{array}$ & $\begin{array}{c}\text { Anhydride, Trifluoroacetic anhydride, } \\
\text { N-Methylbis(trifluoroacetamide) }\end{array}$ \\
\hline Carboxylic acids & $\begin{array}{c}\text { Pentafluoro propanol/pentafluoro } \\
\text { propionic anhydride }\end{array}$ \\
\hline Active hydrogens & $\begin{array}{c}\text { Pentafluoro propanol/pentafluoro } \\
\text { propionic anhydride }\end{array}$ \\
\hline Amides & Heptafluorobutyrylimidazole \\
\hline Amines & $\begin{array}{l}\text { Trifluoroacetic anhydride, } \\
\text { Pentafluorobenzyl chloride, } \\
\text { Heptafluorobutyrylimidazole }\end{array}$ \\
\hline Amino acids & Heptafluorobutyrylimidazole \\
\hline Catecholamines & $\begin{array}{c}\text { Pentafluoropropionic Anhydride, } \\
\text { Heptafluorobutyrylimidazole, }\end{array}$ \\
\hline Nitrosamine & $\begin{array}{l}\text { HFBA, Pentafluoropropionic anhydride, } \\
\text { Trifluoroacetic anhydride }\end{array}$ \\
\hline Sulphonamides & $\begin{array}{c}\text { Trifluoracetic \& Heptafluorobutyric } \\
\text { Anhydride, Pentafluorobenzyl bromide }\end{array}$ \\
\hline
\end{tabular}

Table C

\section{Types of column derivatizations}

Most of the amino acids are not have characteristic UV or visible-light absorption spectra and they are not a fluorescent. So, they are selectively modified to suitable substances to which can showing the fluorescence or visible-light absorption or derivatized and then detected [7]. Column derivatization is a method for the chromatographic analysis of target analyte. Derivatization is the chemical change or modification to the target analyte are discussed in relation to several roles played in HPLC analysis such, as for the separation of polar and non-polar, to enhance chromatographic separations and for detection sensitivity. The derivatization is helpful for improvement of quantification accuracy and stability of analyte to improve the chiral separation. The column derivatizations are mainly categorized into two types.

They are:

- Post-column derivatization

- Pre-column derivatization

\section{Post-column derivatization}

The technique is suitable for the HPLC for analysis of target analyte and detection is for spreading of signal, ease of use and relatively low-cost of the detection hardware, high or routine HPLC analysis are done by choosing the UV-visible absorbance and fluorescent emission methods [8]. Usually, the pre-and post-column derivatization (PCD) techniques are used to overcome the problems with analyte by converting the chromatographically partitioned analytes to derivatives with chromophores for the intense absorption or fluorescence peaks, which will effect the change in the wavelength range (higher region) to avoid the likelihood interferences (Figure 1).

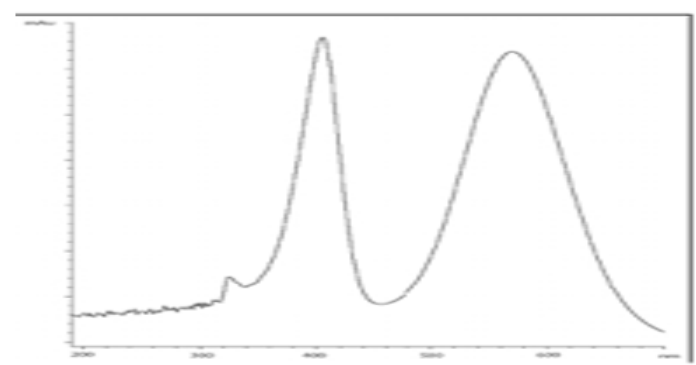

Figure 1: Spectra of an amino acid derivative with Ninhydrin.

The chromatographic separation is achieved by derivatization of analytical compounds in the column by post-column derivatization (PCD) method (Figure 2).

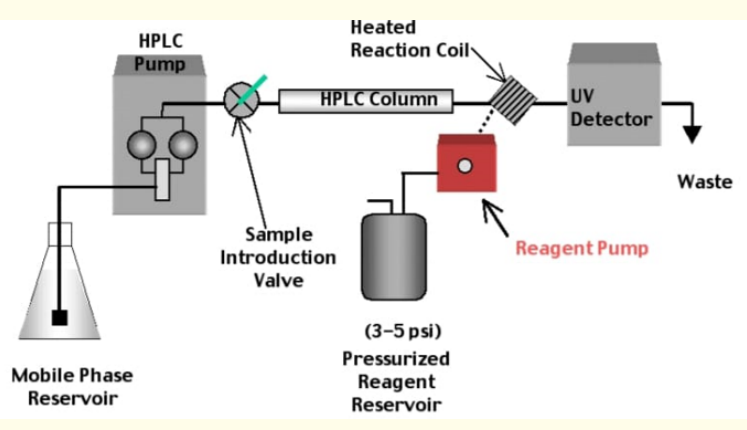

Figure 2: Post-column derivatization. 
$O$-phthalaldehyde (OPA), ninhydrin and fluorescamine are mainly used as derivatizing agents in the post-column derivatization (PCD) [9]. The fluoresceine is less reactive or does not reactive with secondary amino acids. So, the fluoresceine is less used (10\%) in estimation of amines than the other two derivatizing agents. The fluoresceine reacts with primary amino acids in the presence of $\mathrm{pH}$ 9 buffer, the generated derivatives are detected by the fluorescence detector in RP-HPLC (Reverse Phase-High Pressure Liquid Chromatography). The post-column derivatization reduces the reaction time by few seconds. The PCD is carried out in the separation reaction coil. A new type of columns is used in the PCD they are usually termed as AFT (Active Flow Technology) columns [10]:

- PCD techniques provides sensitive and selective approach to detection in liquid chromatography.

- Characteristic moiety information provided by PCD techniques is specific to derivatization reagents in order to decrease sample complexity.

- Conventional PCD methods often involve the use of multiple pumps and reaction coils as well as detector for derivative.

- Fluorescamine reagent and fluorescence detection (FLD) along with reaction flow (RF) chromatography was used for the analysis of amino acids.

- Greater sensitivity was achieved by RF columns when compared to conventional PCD methods, without the need for reaction loops, which resulted in more efficient separation.

- Incompatibility of PCD techniques with modern HPLC columns have been reviewed by jones., et al.

- Several requirements have been described by pickering for successful application of a PCD system. These requirements include reagent stability, reaction speed, reproducibility, derivative solubility, minimal detector response of reagents and uniformity of flow [11].

- There are numerus reviews on LC-PCD techniques that report on simple modification in operational combination with modern technology to minimize eluent reagent consumption band broadening as well as to increase sensitivity [12].

\section{Pre-column derivatization}

Pre-column derivatization is the sufficient method for the analysis of amino acids. The amino acids are derivatized by the derivatizing reagent before entering into the column. After the derivatives are formed, then they are pumped to HPLC (reverse phase). This technique is known as the pre-column derivatization. The agents which are used for derivatization are dansyl derivatives and phenyl thiohydantoin derivatives. These derivatizing reagents interfere with reagent peaks also. So, o-phthalaldehyde and 2-mercaptoethanol are discovered for the process of derivatization in the precolumn derivatization. The only drawback of these two derivatizing agents is non-reactive with secondary amines and secondary amino acids. Various types of reagents are used for pre-column derivatization and UV or fluorometry detection.

Chaitanya G., et al. in 2019, described the following methods:

- $o$-phthalaldehyde method

- $\quad$ PITC method

- Dansylchloride method

o-phthalaldehyde method

Fluorescence detectors were used for the detection and the derivatives were prepared manually. The problems encountered with the use of 2-mercaptoethanol was tackled by the use of an alternative derivatizing agent named 3-mercaotopropionic acid acetonitrile. By the help of this reagent, the analysis work can be done in a time interval of 13 minutes. This helps in the estimation of amino acids in the liver, kidneys and muscles.

\section{PITC method}

This reagent is also called as Edman's reagent. The amino acids are derivatized by reacting them with the reagent and converting them into their thiocarbamyl derivatives. Once, the derivatives are formed, they are then sent to column for further analysis. The thiocarbamyl derivatives are stable for several days under a refrigerated temperature.

\section{Dansylchloride method}

The dansyl chloride derivatives of all primary and secondary amino acids are very widely accepted for the research and estimation work. These derivatives can be detected by using fluorescence detectors. The time required for the derivatization to be completed is between 35 to 50 minutes if the reaction is carried out in dark. After that, the derivatives are ready for the analysis work in the RP-HPLC. 
A simple two step pre column derivatization technique was developed by the Rainer Schuster for the analysis of primary and secondary amino acids altogether. The above described derivatizing agents have some drawbacks in the application of analysis and estimation studies of target analyte. This pre column derivatization was developed in order to overcome the problems with derivatizing agents.

- Step 1: The first step of this technique is the primary amino acids are reacted with the o-phthalaldehyde and 3-mercaptopropionic acid and produces the secondary amines.

- Step 2: The second step of this technique is the reaction of the secondary amino acids with the reagent 9-Fluorenylmethyl-chloroformate (FMOC).

Then the primary and secondary amino acids are ready to introduce into the reverse phase column for the separation, it takes 15-20 minutes for complete estimation. It is completely automated procedure of derivatization. The samples and the reagents are collected, transferred into a common vial and are mixed thoroughly.

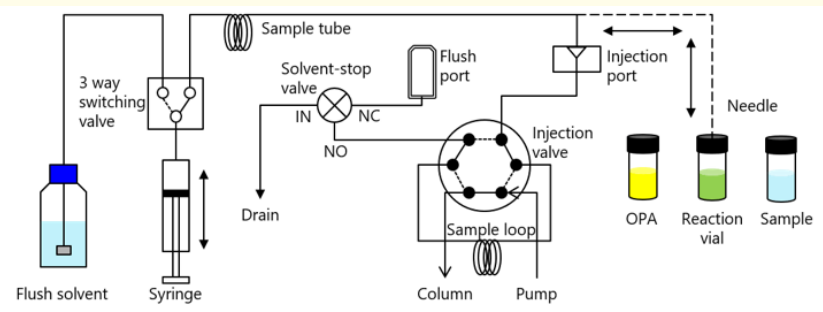

Figure 3: Mechanism of the pre-column derivatization technique (AS-4550).

\section{Determination of amines or amino acids by RP-HPLC}

The pre-and post-column derivatization techniques are useful for the determination of amino acids or amines by the derivatization of target analysis. RP-HPLC and UV detection are generating enhanced separation, by improved sensitivity and faster analysis than the post-column (OPA) derivatization, ion-exchange HPLC and fluorescence detection.

Stephan E., et al. (1985) developed a method for selective analysis of secondary amines or amino acids. $o$-phthalaldehyde and 2-mercaptothanol are used as a derivatizing agent for the sec- ondary and primary amino acid derivatives. The secondary amino acids are derivatized by 9-fluorinylmethyl chloroformate (FMOC). Both primary and secondary amino acids are analysed by using a basic solution. The secondary amino acids convert into primary amino acids by the same reaction mixture.

\begin{tabular}{|c|c|c|}
\hline Method & $\begin{array}{l}\text { Pre-column/ } \\
\text { UPLC }\end{array}$ & $\begin{array}{l}\text { Post-column/ } \\
\text { HPLC }\end{array}$ \\
\hline Instrument & $\begin{array}{l}\text { Waters ACQUITY } \\
\text { UPLC system }\end{array}$ & $\begin{array}{c}\text { Hitachi L-8800 } \\
\text { amino acid ana- } \\
\text { lyzer }\end{array}$ \\
\hline Column & $\begin{array}{c}\text { Waters AccQ-Tag } \\
\text { Ultra } \\
\text { C18 } 1.7 \mu \mathrm{m} \\
2.1 \times 100 \mathrm{~mm}\end{array}$ & $\begin{array}{c}\text { Hitachi AAA } \\
\text { special analysis } \\
\text { column } \\
4.6^{\times} 60 \mathrm{~mm}\end{array}$ \\
\hline $\begin{array}{l}\text { Detection } \\
\text { Wavelength }\end{array}$ & $260 \mathrm{~nm}$ & $\begin{array}{c}440 \mathrm{~nm}(570 \mathrm{~nm} \\
\text { for pro) }\end{array}$ \\
\hline $\begin{array}{l}\text { Derivatization re- } \\
\text { agent }\end{array}$ & $\begin{array}{c}\text { 6-aminoquinolyl- } \\
\text { N-hydroxysuccin- } \\
\text { imidyl carbamate } \\
\text { (AQC) }\end{array}$ & Ninhydrin \\
\hline Run time & $9.5 \mathrm{~min}$ & $84.4 \mathrm{~min}$ \\
\hline Injection Volume & $1 \mu \mathrm{L}$ & $20 \mu \mathrm{L}$ \\
\hline Standard & $\begin{array}{l}\text { Waters amino } \\
\text { acid standard }\end{array}$ & $\begin{array}{c}\text { Thermo Scientific } \\
\text { amino acid stan- } \\
\text { dard }\end{array}$ \\
\hline Internal Standard & NorValine & NorLeucine \\
\hline Sample & $\begin{array}{c}\text { Bovine Serum } \\
\text { Albumin (BAS) } \\
\text { hydrolysate }\end{array}$ & $\begin{array}{c}\text { Bovine Serum } \\
\text { Albumin (BAS) } \\
\text { hydrolysate }\end{array}$ \\
\hline
\end{tabular}

Table 1: Methods and materials Shiqian Z., et al. in 2012.

Two amino acid analysis methods are comparing in terms of resolution and sensitivity.

- $\quad$ RP-UPLC (Ultra - High Performance Liquid Chromatography) coupled with pre-column. 6-amino quinolyl-N-hydroxysuccinimidyl carbamate (AQC) derivatization.

- Cation-exchange HPLC coupled with post-column ninhydrin derivatization, considered as reference method due to its robust nature.

The example chromatograms of amino acid standard $(200 \mathrm{nmole} / \mathrm{mL})$ from both methods are shown in figure 4 . The 
resolution and sensitivity of pre-column/UPLC method is significantly better than that of post-column/HPLC method.

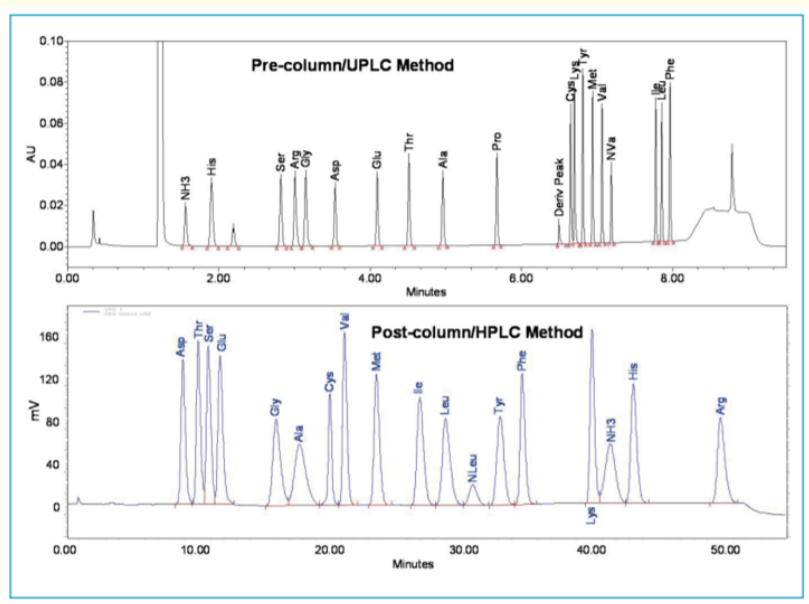

Figure 4: Example chromatograms.

The resolution and sensitivity of pre-column RP-UPLC method is significantly better than post-column HPLC method. The repeatability of instrument was evaluated as \%RSD in terms of retention time, peak area of each amino acid in five consecutive injections of standard.

For each amino acid, the linearity of standard curve was evaluated in range of $20 \mathrm{nmol} / \mathrm{mL}$ to $200 \mathrm{nmol} / \mathrm{ml}$. The linearity and $\%$ RSD results are listed in table 2 . The determination of coefficient of each amino acid standard curve is greater than 0.99 . The \%RSD of peak area and retention time of each amino acid peak is $\leq 1.0 \%$ for both the methods.

- Pre-column derivatization/UPLC method.

- Post-column derivatization/HPLC method.

\section{Alternative methods for amino acid estimations}

Richard P. B., et al. (1994) developed another method for the simultaneous estimation of primary and secondary amino acids by using capillary electrophoresis. Then the separated sample is electro-oxidized on the copper electrodes so that we can quantify the samples. The only condition of this process to work efficiently is that the electrode requires a completely alkaline ambience around

\begin{tabular}{|c|c|c|c|c|c|c|}
\hline \multirow{3}{*}{$\begin{array}{c}\text { Amino } \\
\text { acid }\end{array}$} & \multirow{3}{*}{\begin{tabular}{|c|}
$\begin{array}{c}\text { Linearity } \\
\left(\mathbf{R}^{\mathbf{2}}\right)\end{array}$ \\
\\
$\begin{array}{c}\text { Pre- } \\
\text { UPLC }^{\mathbf{a}}\end{array}$ \\
\end{tabular}} & & \multicolumn{4}{|c|}{$\begin{array}{c}\text { Instrument Repeatability } \\
\text { (\%RSD) }\end{array}$} \\
\hline & & \multicolumn{2}{|c|}{ Retention Time } & \multicolumn{2}{|c|}{ Peak Area } & \multirow[b]{2}{*}{$\begin{array}{l}\text { Post- } \\
\text { HPLC }^{b}\end{array}$} \\
\hline & & $\begin{array}{l}\text { Post- } \\
\text { HPLC }^{b}\end{array}$ & $\begin{array}{c}\text { Pre- } \\
\text { UPLC }^{\mathrm{a}}\end{array}$ & $\begin{array}{l}\text { Post- } \\
\text { HPLC }^{b}\end{array}$ & $\begin{array}{c}\text { Pre- } \\
\text { UPLC }\end{array}$ & \\
\hline His & 0.9998 & 1.0000 & $1.0 \%$ & $0.0 \%$ & $0.4 \%$ & $0.7 \%$ \\
\hline Ser & 1.0000 & 1.0000 & $0.4 \%$ & $0.1 \%$ & $0.3 \%$ & $0.5 \%$ \\
\hline Arg & 0.9998 & 1.0000 & $0.4 \%$ & $0.0 \%$ & $0.3 \%$ & $0.7 \%$ \\
\hline Gly & 0.9999 & 1.0000 & $0.3 \%$ & $0.1 \%$ & $0.3 \%$ & $0.6 \%$ \\
\hline Asp & 0.9995 & 1.0000 & $0.3 \%$ & $0.2 \%$ & $0.3 \%$ & $0.5 \%$ \\
\hline Glu & 0.9996 & 1.0000 & $0.3 \%$ & $0.1 \%$ & $0.3 \%$ & $0.5 \%$ \\
\hline Thr & 1.0000 & 1.0000 & $0.4 \%$ & $0.1 \%$ & $0.4 \%$ & $0.5 \%$ \\
\hline Ala & 0.9998 & 1.0000 & $0.6 \%$ & $0.2 \%$ & $0.3 \%$ & $0.6 \%$ \\
\hline Pro & 0.9999 & 0.9998 & $0.4 \%$ & $0.1 \%$ & $0.3 \%$ & $0.8 \%$ \\
\hline Cys & 0.9998 & 0.9999 & $0.2 \%$ & $0.0 \%$ & $0.4 \%$ & $0.7 \%$ \\
\hline Lys & 0.9986 & 1.0000 & $0.2 \%$ & $0.0 \%$ & $0.7 \%$ & $0.7 \%$ \\
\hline Tyr & 0.9996 & 1.0000 & $0.2 \%$ & $0.0 \%$ & $0.3 \%$ & $0.6 \%$ \\
\hline Met & 0.9999 & 1.0000 & $0.2 \%$ & $0.0 \%$ & $0.3 \%$ & $0.6 \%$ \\
\hline Val & 0.9999 & 1.0000 & $0.2 \%$ & $0.0 \%$ & $0.3 \%$ & $0.6 \%$ \\
\hline Ile & 1.0000 & 1.0000 & $0.2 \%$ & $0.0 \%$ & $0.3 \%$ & $0.6 \%$ \\
\hline Leu & 1.0000 & 1.0000 & $0.2 \%$ & $0.0 \%$ & $0.3 \%$ & $0.6 \%$ \\
\hline Phe & 0.9996 & 1.0000 & $0.2 \%$ & $0.0 \%$ & $0.3 \%$ & $0.6 \%$ \\
\hline
\end{tabular}

Table 2: Linearity and instrument repeatability results Shiqian Z., et al. in 2012.

it and that can be achieved by using around 50-100 mM sodium hydroxide $(\mathrm{NaOH})$. The detection limit of amino acids using this CE method was found to be around 1-10 fmol. One of the main advantages of using cu electrodes is that when we use electrodes other than that of copper, they require a pulse potential to operate, whereas, in the case of copper electrode, no such condition exists and it can operate on a constant potential only.

Xuimei J., et al. in 2009 devised another improvement in the estimation of amino acids by capillary electrophoresis (CE) technique. They developed an online sweeping technique for the estimation of amino acids simultaneously. With the help of this online sweeping technique, the LOD or limit of detection for the samples came to value of 0.1 to $0.5 \mu \mathrm{mol} / \mathrm{L}$. This technique saved the time and efforts that were being consumed in other primitive techniques for the same purpose. The next step is the direct UV detection of the 
samples after separation. By using this method, till now, various real-life samples of amino acids in the human urine, saliva and other secretions have been analysed. The direct UV detection can be done by using copper electrodes as the centre ion and this allows the detection at somewhat shorter wavelength of $254 \mathrm{~nm}$, wavelength at which most of the amino acids are generally analysed.

Zhaohui., et al. in 2001 developed a novel method of capillary electrophoresis with laser induced fluorescence for the detection of the amino acid samples in the human brain. This could be done by derivatizing the amino acid samples by using a different agent other than the conventionally used ones, that is 5-flourylquinoline-3- carboxaldehyde. This technique is of special significance where the sample is of biological origin and the available amount of the sample is too less to be analysed by the usual analytical techniques. An argon ion laser was applied to the samples for the purpose of inducing fluorescence in the non-fluorescent samples which were not able to exhibit the phenomenon of fluorescence naturally. Subsequently, the derivatized amino acid samples were examined for the qualitative and quantitative analysis. This LIF (Laser Induced Fluorescence) technique was more advantageous over the other conventional techniques in various aspects like this technique enhanced the sensitivity of the analytical procedure hence bringing down the detection limits to a very less value. Another advantage that this technique serves is its very less sample demand. This requires a very less volume of the sample for an efficient analysis work. Hence this technique is less time consuming, inexpensive and precise.

\section{Pre and post column detections}

The pre and post-column derivatization are the analytical methods used for the selective, sensitive and improved detection of the analyte by signal enhancement. The post-column derivatization methods are generally altering or reducing the time of reaction for few seconds. The rate of reaction is enhanced by the derivatization of the target analyte by the derivatizing agents. These pre and post-column methodologies are useful for many types of the highvolume analytical applications required across the pharmaceutical value chain, drug screening, clinical trials, product quality control, patient diagnostic and therapeutic monitoring.

The comparison of post-column and pre-column derivatization Shinichi O., et al. in 2015.

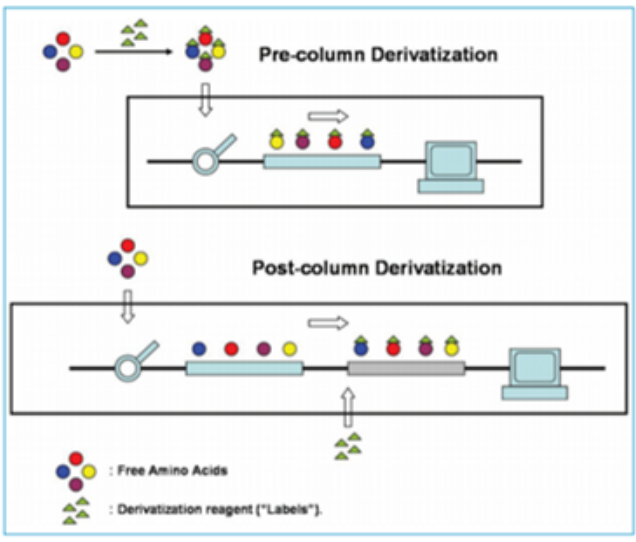

Figure 5: Pre-column derivatization vs. post-column derivatization.

\section{Applications}

- PCD method is useful for the effective analysis of the target analyte.

- Alteration or reduction in the reaction mixture time.

- Enhancement in the chromatographic resolution and signal enhancement [13].

- Determination of primary and secondary amino acids.

Estimation of selective amino acids and vitamins [14].

PCD methods are used for drug screening.

\section{Conclusion}

This paper describes those various analytical techniques are used in HPLC for the effective and selective analysis of target analyte. These pre-and post-column techniques are useful for estimation of determination of primary amino acids and secondary amino acids. The amino acid derivatives are detected by the fluoresce detector to. Capillary electrophoresis (CE) is the one of the alternative methods for the estimation of amino acids. However, the pre-and post-column methods are enhancing sensitivity and precision of target analyte analysis. The repeatability, linearity and recovery of both methods met the requirements to determine amino acid composition and content of proteins. 


\begin{tabular}{|c|c|c|}
\hline Post-column derivatization & Advantages & Disadvantages \\
\hline $\begin{array}{l}\text { once the reaction system is } \\
\text { optimized, it can be used for a } \\
\text { wide range of samples, including } \\
\text { fermentation extracts, making it } \\
\text { suitable for routine analysis with } \\
\text { excellent quantitation perfor- } \\
\text { mance. }\end{array}$ & $\begin{array}{l}\text { Reactions can be automated. } \\
\text { Outstanding quantitation capability and } \\
\text { reproducibility. } \\
\text { Because sample components are sepa- } \\
\text { rated in the column before the reaction, } \\
\text { it is not affected by the sample matrix } \\
\text { during reaction with the derivatizing } \\
\text { reagent. }\end{array}$ & $\begin{array}{l}\text { Difficult to use for high-sensitivi- } \\
\text { ty analysis. } \\
\text { Relatively high reagent consump- } \\
\text { tion. } \\
\text { Limited variety of derivatizing } \\
\text { reagents can be used. } \\
\text { Cannot use rapid reversed phase } \\
\text { chromatography. }\end{array}$ \\
\hline Pre-column derivatization & Advantages & Disadvantages \\
\hline \multirow[t]{2}{*}{$\begin{array}{l}\text { Method appropriate for higher- } \\
\text { sensitivity analysis of a somewhat } \\
\text { limited variety of samples, such } \\
\text { as purified amino acids. }\end{array}$} & $\begin{array}{l}\text { Consumes less reagent. } \\
\text { Simpler instrument configuration. } \\
\text { Allows increasing sensitivity. } \\
\text { Wide availability of derivatizing re- } \\
\text { agents allows selecting the reagent best } \\
\text { suited to the type of detector (such as } \\
\text { UV, VIS or RF) } \\
\text { Allows using rapid reversed-phase } \\
\text { chromatography. }\end{array}$ & $\begin{array}{l}\text { Derivatization reaction efficiency } \\
\text { is affected by sample matrix. } \\
\text { Reaction products are often } \\
\text { unstable and can often effect } \\
\text { quantitation results. }\end{array}$ \\
\hline & Post-column derivatization & Pre-column derivatization \\
\hline Advantage & $\begin{array}{c}\text { Automated process } \\
\text { Great quantitative performance and } \\
\text { repeatability } \\
\text { Minimized sample matrices effect when } \\
\text { reacting with reagents }\end{array}$ & $\begin{array}{l}\text { Low consumption of derivatiza- } \\
\text { tion reagents } \\
\text { Simple system configuration } \\
\text { Reagent selection options avail- } \\
\text { able depending on detector type } \\
\text { Available with reverse-phase } \\
\text { chromatography }\end{array}$ \\
\hline Disadvantage & $\begin{array}{l}\text { Significant consumption of derivatiza- } \\
\text { tion reagents } \\
\text { Not available for reverse-phase chroma- } \\
\text { tography }\end{array}$ & $\begin{array}{c}\text { The efficiency of derivatization } \\
\text { reaction depends on reagent } \\
\text { matrices } \\
\text { Poor area repeatability } \\
\text { Only a few compounds are } \\
\text { detacable }\end{array}$ \\
\hline
\end{tabular}

Table d

Both methods showed their advantages and dis-advantages.

Pre-column UPLC method provides better resolution and sensitivity with much shorter run time (9.5 min). The consumption of derivatization reagent is very small so more expensive reagent is can be used. The derivatization step in pre-column UPLC method is labour-intensive and reaction efficiency may be affected by sample 
matrix [15]. The Reaction Flow-PCD method resulted in a decrease in the number of sample molecules undergoing derivatization, there was as a consequence a reduction in the fluorescence response when comparison was made to a conventional PCD technique [16]. In post-column HPLC method, the derivatization reaction is automated (online) and not affected by sample matrix. This offers excellent quotative performance and reproducibility. The total runtime of each sample using post-column HPLC is as long as $84.8 \mathrm{~min}$ and this method requires a dedicated instrument. After the reaction system is optimized, for routine quotative analysis, post-column HPLC method is good choice. For studying special amino acids and for screening derivatization reagents, pre-column UPLC method is good choice.

\section{Bibliography}

1. Jones A., et al. "Post column derivatization using reaction flow high performance liquid chromatography columns". Journal of Visualized Experiments : JoVE 2.110 (2016): 1-13.

2. Ai Y., et al. "Rapid Determination of the Monosaccharide Composition and Contents in Tea Polysaccharides from Yingshuang Green Tea by Pre-Column Derivatization HPLC". Journal of Chemistry 2016 (2016): 5.

3. Mckeet T MJ. "Amino acids, proteind and peptides". in biochemistary the molecular basies of life (2015): 1-59.

4. Sofiqul I., et al. "Review Article Analytical Methods For The Determination Of Aminoglycosides Antibiotics By Chromatrographic Technique". International Journal of Pharmacy and Pharmaceutical Sciences 12.4 (2020).

5. Zhao J., et al. "Rapid and Effective Sample Cleanup Based on Polyvinylpyrrolidone-Coated Magnetite Nanoparticles Coupled with New Pre-Column Derivatization for Determination of Aflatoxins B 1, B 2, G 1 and G 2 in Animal Feeds by High-Performance Liquid Chromatography wi". Journal of the Brazilian Chemical Society 30.9 (2019): 1814-1824.

6. F Orata. "Derivatization Reactions and Reagents for Gas Chromatography Analysis, Advanced Gas Chromatography - Progress in Agricultural, Biomedical an d Industrial Applications, 2019, January 2012: 83-108.

7. L- AAA Ozawa S. Advances in amino acid analysis 6 (2015): 33-43.

8. "Amino Acid Analysis, Pickering Laboratories".
9. Chaitanya Goswamia., et al. "Simultaneous estimation of Amino acids by using HPLC". International Journal for Innovative Research in Science and Technology 4.2 (2019): 1-8.

10. Sercan CP AJ. "Post column derivatization of amino acids using reaction flow chromatography columns with fluorescence detection: A fast new approach to selective derivatization techniques". Journal of Liquid Chromatography and Related Technologies 40 (2017): 83-92.

11. Jones A., et al. "Post Column Derivatisation Analyses Review. Is Post-column Derivatisation Incompatible with Modern HPLC Columns". Analytica Chimica Acta 2015 (889): 58-70.

12. Laboratories P. “Operator Manual - Pinnacle PXC Post-Column Derivatization”. Instrument Pick Lab (2016).

13. AlShehri MM and AlMeshal MA. "Pre-column derivatization HPLC method for rapid and sensitive determination of free and total formaldehyde in hair straightening products". Arabian Journal of Chemistry 13.1 (2020): 2096-100.

14. Fan B., et al. "A novel and sensitive method for determining vitamin B3 and B7 by pre-column derivatization and high-performance liquid chromatography method with fluorescence detection". PLoS One 13.6 (2018): 1-15.

15. Zhu S., et al. "Comparison of two Amino Acid Analysis Methods: Pre-column Derivatization / RP-UPLC M1067". Comparison of two Amino Acid Analysis Methods: Pre-column Derivatization / RP-UPLC vs . Post-column Derivatization / Cation-Exchange HPLC.

16. Pravadali-cekic S., et al. "Postcolumn derivatization of amino acids using reaction flow chromatography columns with fluorescence detection: A fast new approach to selective derivatization techniques". Journal of Liquid Chromatography and Related Technologies 40.2 (2017): 83-92.

\section{Volume 5 Issue 8 August 2021 \\ (C) All rights are reserved by $\mathrm{CH}$ Prudhviraju., et al.}

